\title{
Structural Insulated Panels: State-of-the-Art
}

\author{
Panjehpour $^{1 *}$, Eric Wooi Kee Loh $^{2}$ and Deepak TJ ${ }^{3}$ \\ ${ }^{1}$ Civil Engineering Department, INTI International University, Malaysia \\ ${ }^{2}$ Management Development Institute of Singapore, Singapore \\ ${ }^{3}$ Civil Engineering Department, Linton University College, Malaysia
}

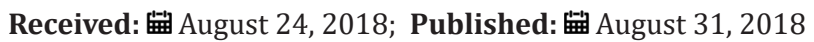

*Corresponding author: Panjehpour, Civil Engineering Department, Centre for Advanced Concrete Technology (CACT), Faculty of Engineering and Quantity Surveying, INTI International University, Nilai, Malaysia

\begin{abstract}
This article aims to review and illuminate the latest research conducted on structural insulated panels (SIP) together with the latest information of the current experiment carried out by the authors. The authors attempt to weight up both sides of argument regarding the design methods of SIP: affordability and applicability in construction industry, by taking up-to-date concrete technology and manufacture into consideration. The article primarily shines a light on the new material used for SIP's skin and core. The fiber-carbon-reinforced polymer plate, glass-fibre reinforced magnesia cement boards, E-glass/polypropylene and glassfibre-reinforced polymer grid have recently been proposed for SIP components material. Besides, the performance of SIPs against wind load is investigated. Far little attention has been paid to SIP connections is in recent research. Economically, there is a need to innovatively alter an affordable material for SIP components to set the scene for its mass production.
\end{abstract}

Keywords: Structural Insulated Panel; Composite Structure; FRP

\section{Introduction}

The modular and prefabricated houses are becoming more popular as today's customers prefer fast-constructed building in favor of time-consuming processed conventional building [1]. Consequently, due to the demand for prefabricated elements of building the need for structural insulated panels (SIPs) has been highlighted in recent years. Being lightweight, thermal performance and speed of installation are the main advantages of SIP which attracted the researchers' attention. SIPs can serve the building as both wall and floor. Since emergence of SIP design, in 1930, proposed by the Forest Products Laboratory in U.S., there have been issues regarding its components material, connections, shear connectors and fire resistance [1]. Among aforementioned issues, the propose of an alternative material has attracted researchers attention nowadays [1-7]. The conventional material used for SIP skin are sheet metal, oriented strand board (OSB), plywood, cement board. Fibre-reinforced polymer (FRP) plate has been proposed as SIP skin, and also as shear connectors between the two skins of SIP [7-8]. Besides, glass-fibre reinforced magnesia cement board and E-glass/polypropylene laminate have been recently proposed to alter traditional SIP skin material [9-10]. The use of carbon-fibrereinforced polymer (CFRP) sheet for strengthening of SIP skins against lateral loads is becoming popular. Wood wool and cement board are used as SIP skin while expanded polystyrene (EPS) is used as SIP core in this experiment.

Excluding the scale reduction of specimens, the process of SIP assemblage in factory is simulated in this experiment. SIP as an external wall must be resistance enough against wind load. The dynamic response of SIPs subjected to windborne debris impact was examined and came to a conclusion that penetration resistance capacity of SIP is governed by toughness and flexibility of skin material [8]. The SIPs made of EPS core and metal skins was experimentally tested against windborne debris and theoretically evaluated using numerical models developed using LS-DYNA, an advanced general-purpose multiphasic simulation software package, to simulate their dynamic behavior [8]. As a general construction material standard, SIP shall be certified regarding the fire test as it is one of the significant stage of building products commercialization. The full-scaled natural fire tests on the buildings made of SIPs concluded that the SIPs using OSB and EPS met the requirements performance criterion based on UK building regulation [11]. By and large, this article provides the state-of-the art of SIP in order to set the stage for further research to enhance the SIP design. Looking from the economic view, the afore mentioned proposed SIP designs might not be able to compete with those of 
traditional designs. There is still a need for alteration of affordable material for SIP components, particularly SIP skin. Moreover, the future proposed SIP designs should be simple in order to set the scene for mass production and commercialization purposes.

\section{The state-of-the art}

SIPs are special type of precast sandwich panels. These composite building elements are composed of a thick layer of insulating core which is tightened between two thin layers of structural board. The use of SIP dates back to 1930, when the idea of stress skinned panels for building proposed by Forest Products Laboratory in the U.S. This idea has been improving by proposing methods of configuration and installation of SIP as well as proposing alternative material for its skin and core. Sheet metal, oriented strand board, plywood and cement board have been commonly utilised as SIP skin material while expanded polystyrene, extruded polystyrene and polyurethane have been utilised as its core. Figure 1 illustrates two houses made of SIPs. The use of FRP has been rapidly increasing in construction industry particularly for repair and strengthening structural concrete elements [12,13]. A SIP using FRP plates as shear connectors, as shown in Figure 2, was proposed and was analysed by finite element modeling. The shear connectors in design of SIPs has always been an issue as the core of SIP made of soft material may not resist against the shear loads. The three forms of discrete, segmental and continuous connectors were utilised in this study. The proposed SIPs made of EPS foam, FRP plate connectors and ordinary concrete were tested under four-point bending load configuration to evaluate bending failure [8]. However, the design of SIP in this research may not be able to compete with conventional SIP regarding the overall cost.

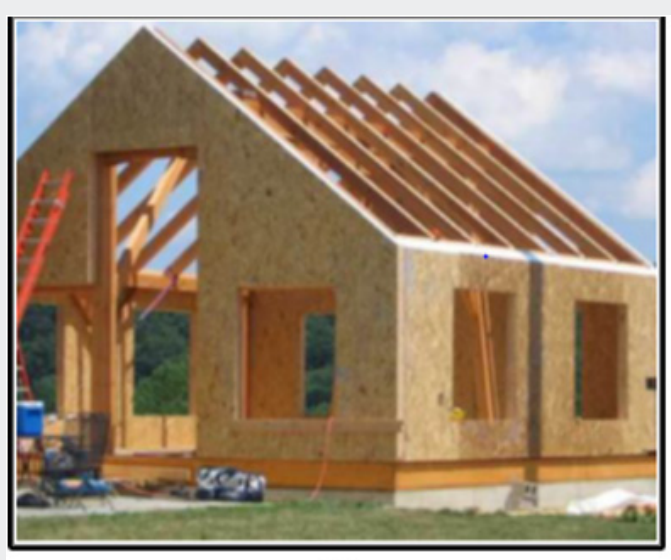

(a)

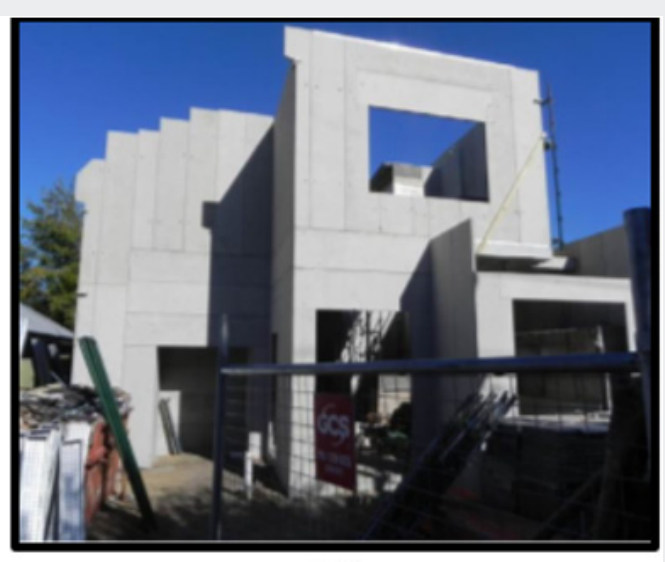

(b)

Figure 1: (a) SIP house with OSB skin [8]; (b) SIP house with fiber cement skin [8].

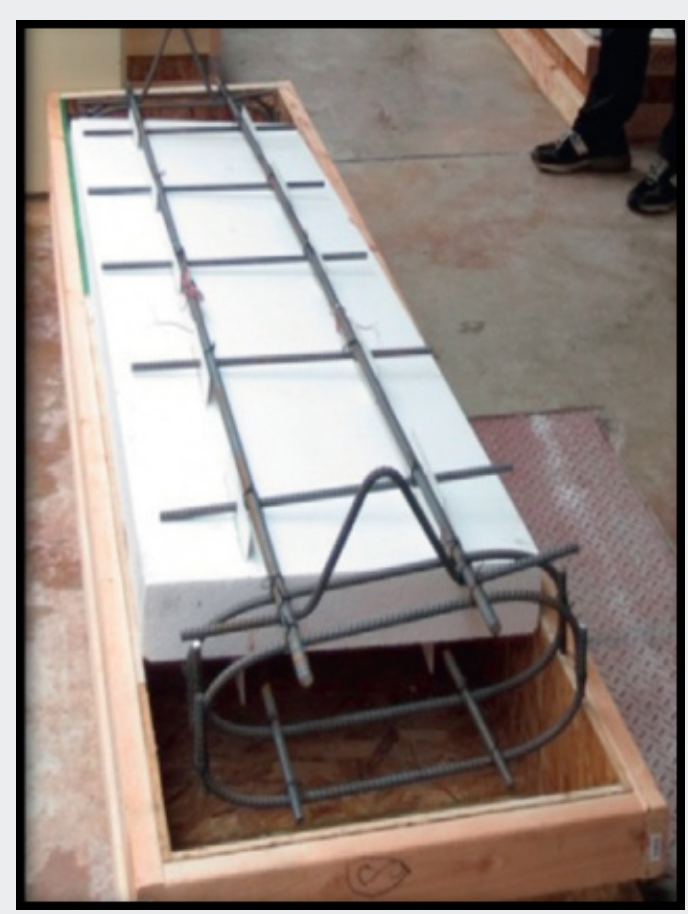

Figure 2: Cage, installation and shear connectors of proposed SIP [8]. 
FRP plates were recently put forward to confine top and sides of SIP in a research. The method of dry bond between concrete and FRP plates was adopted in favor of wet bond. FRP plates could act as water barriers which gave more weight to the proposed design of SIP. Overall, the bending tests on scaled and full scale proposed SIPs concluded their better performance compared to traditional solid sandwich panels [6]. The authors of this review article, have recently started a research investigation on SIPs to alter the conventional material of its skin for strengthening purposes. The use of carbon fibre-reinforced polymer (CFRP) sheets, in one, two and three layers, in the interface of the skin and the core, with wet bond, is under an experimental evaluation for buckling behavior of SIP under lateral load to increase its lateral resistance. The skin is made of wood wool and cement board while the core is made of EPS in this experiment. The CFRP-strengthened skins are tightened with core, by applying epoxy and placing the assembled SIPs under uniformly vertical compression using concrete blocks. Figure 3. illustrates the material used and also compression method in this experiment. The primary objective of the experiment is the strengthening of SIPs regarding its application as load-bearing wall. This research emphasises on the lateral loads imposed by wind, in high-rise building where SIPs are used as external walls. Recently, the resistance capacity of SIPs against high speed localized impact caused by windborne debris has been considered in another research.

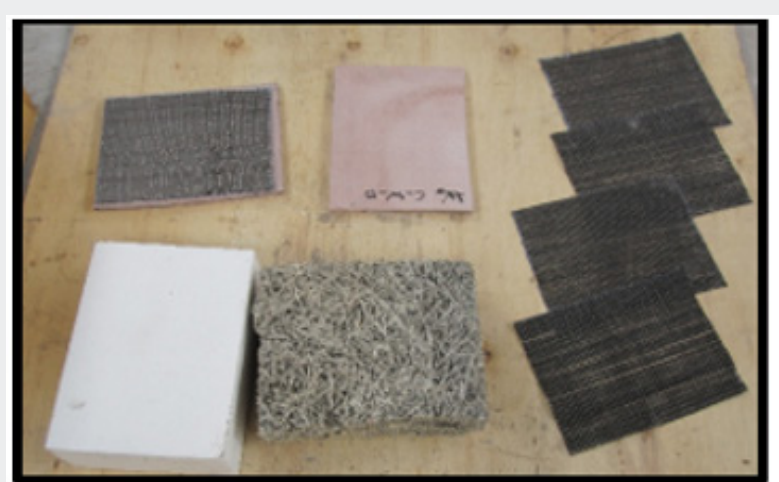

(a)

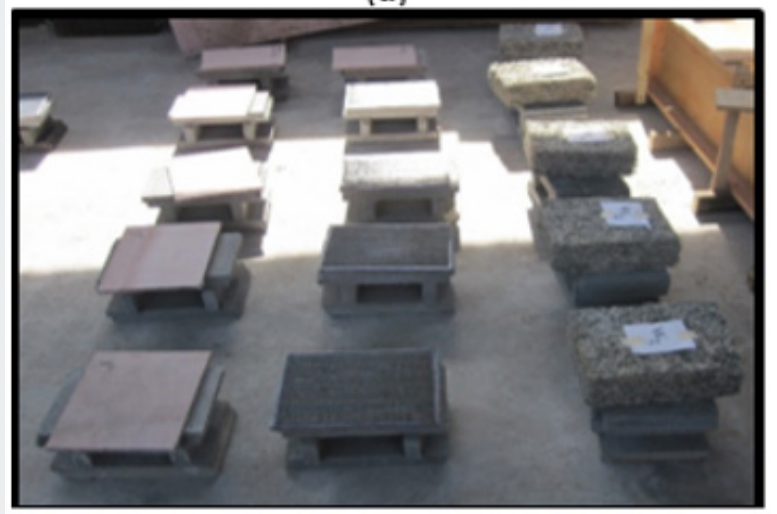

(c)

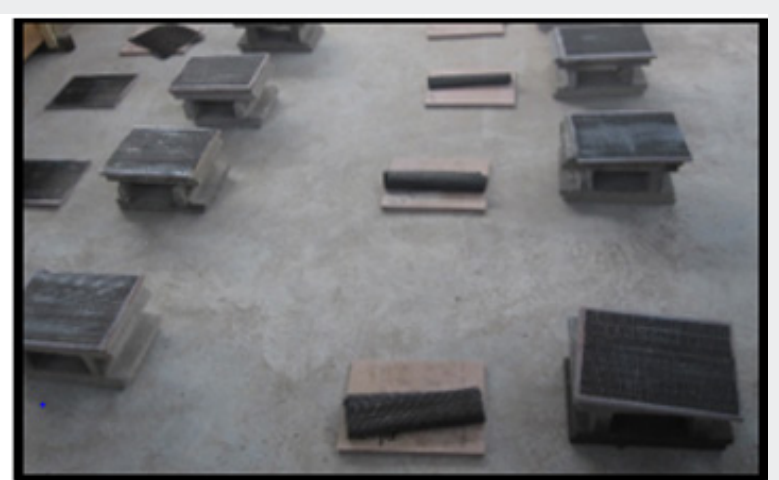

(b)

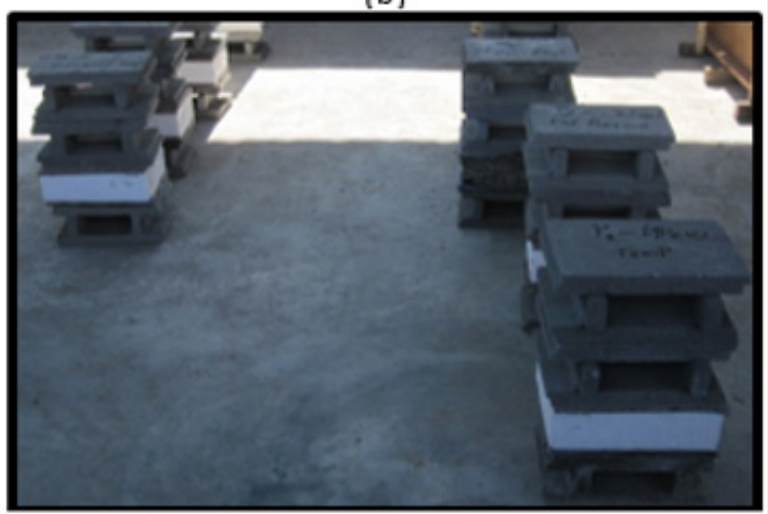

(d)

Figure 3: (a) Cement board, wood wool, CFRP sheet and EPS; (b) cement board skin strengthened with CFRP sheet; (c) strengthened skins and wood wool before assembling SIPs; (d) SIP under uniform compression using concrete blocks.

The dynamic response of SIPs made of EPS and OSB subjected to windborne debris impact was evaluated regarding the penetration resistance capacity. The length of penetration was a key factor in this study. It concluded that the penetration resistance capacity of SIP is governed by toughness and flexibility of skin material [8]. The SIPs made of EPS core and metal skins were experimentally tested against windborne debris and theoretically evaluated using numerical models developed using LS-DYNA, an advanced generalpurpose multiphasic simulation software package, to simulate their dynamic behavior [14]. Apart from FRP material, the use of glassfibre reinforced magnesia cement boards has been proposed by researchers for the skin of SIP. The strength, deformability, failure mode, impact resistance and gradient temperature of full scale SIP panels using this material were experimentally evaluated. The finite element modeling results were in good agreement with findings of research. The research concluded that the proposed SIPs overcome deficiencies of traditional SIPs [10].

In 2013, the E-glass/ polypropylene laminate was proposed for SIP skin in order to overcome the deficiency of poor impact resistance of traditional SIP skin made of OSB. This research emphasised on retaining all energy-saving benefits of the traditional SIPs [9]. Regarding construction design for seismic loading, the effect of cyclic loading on the composite behavior of SIPs made of EPS foam and glass-fibre-reinforced polymer (GFRP) grid as shear connector was evaluated as the test set up is shown in Figure 4. 


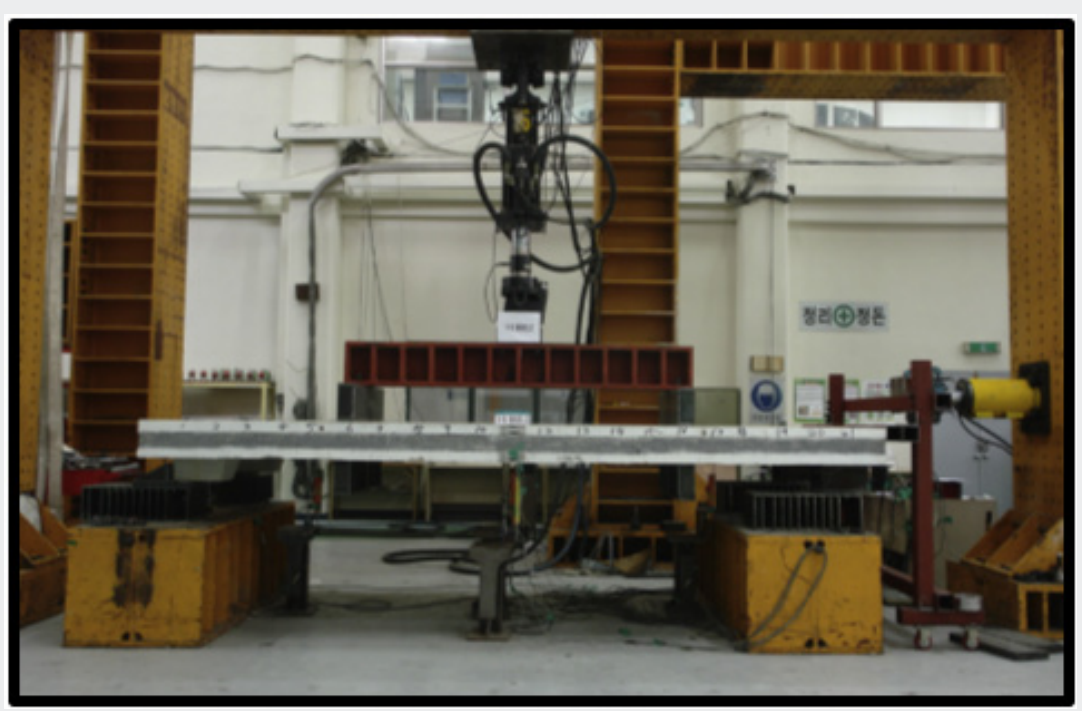

Figure 4: Test set up for SIP using GFRP as shear connector [3].

The specimens with similar configurations, were tested under cyclic and monotonic loading. The results showed a lower performance of SIP under cyclic loading than monotonic loading. This was due to the cumulative fatigue loading which damaged the GFRP strands and debonded the interface between concrete and insulation [13]. Moreover, the dynamic modeling of structural concrete insulated panels have been theoretically proved, using finite element modeling, to suit for the design of energy efficient building in seismic area in a comprehensive study. In addition, this study has concluded that, the SIP using polystyrene foam, as insulating core material, was found as the superior to other wall systems regarding sound proofing as well as heating and cooling insulation [2].

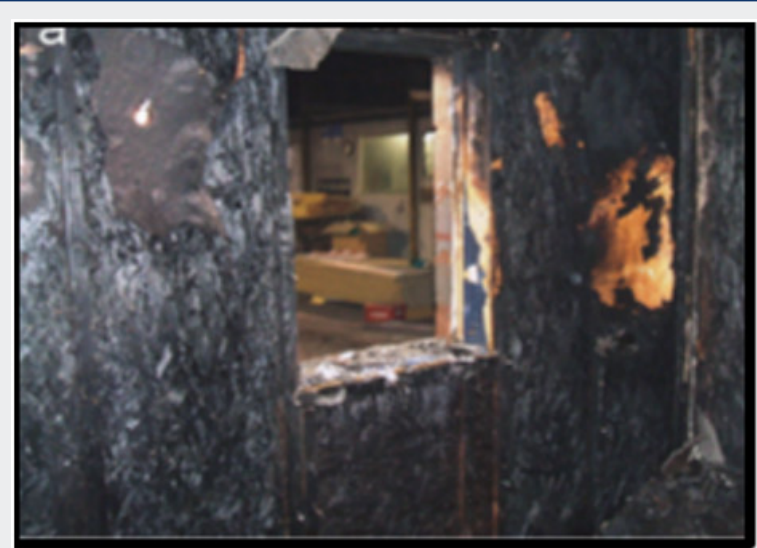

(a)

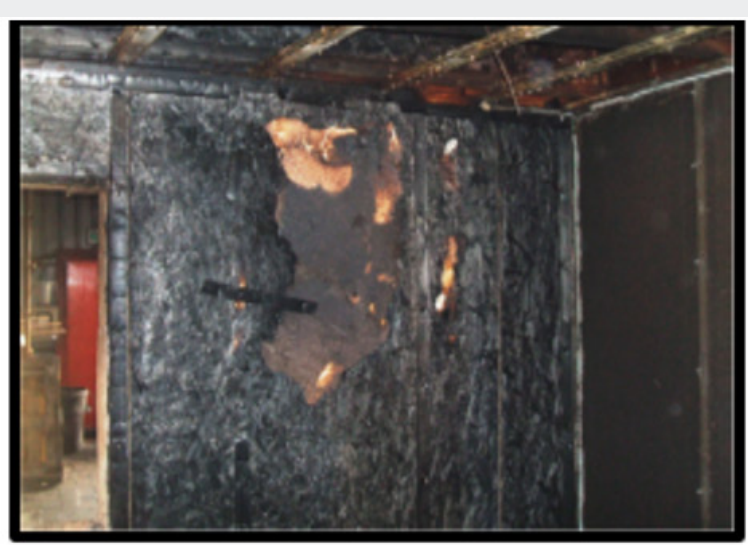

(b)

Figure 5: Different view of SIP-made building after fire test [11].

Above all, the fire resistance of SIPs has always been a concern among researchers. A full-scaled natural fire test, which can rarely be found among experimental tests due to its high cost, was recently conducted on four two-storey buildings made of SIPs as illustrated in Figure 5. The SIPs made of OSB and Expanded polystyrene (EPS) were used for two buildings while OSB and Polyurethane (PUR) were used for the other two. The fire test was conducted using softwood timber cribs, with 30 and 60-min durations. It was concluded that theproposed SIPs met the requirements, proposed in document B, based on UK building regulation. Despite the significant deflection of floor, exceeding span/20, no collapse was observed for floors. In addition, there was no collapse or considerable deflection of wall in this test. The researchers attempted to identify the fire spread mechanism in the experimental building, via parameters effective in fire spreading [11].

\section{Conclusions}

This article provide the state-of-the art of SIP to set the stage for further research on improvement of SIP design. It has gone some ways towards enhancing our understanding of SIP design. The review has shown that among the current issues on the design of SIP, the use of new and affordable material for SIP skin is needed. In recent years, there has been no attention to the issue of SIP connections together and to other building elements. This issue is essentially needed to be investigated in further research 
as poor fitment of SIP connections reduces the insulation of entire building. Looking from economic view, the recent proposed SIP designs might not be able to compete with conventional wall and floor designs. There is still a need to alter affordable material in the design of SIP. Moreover, the proposed SIP designs are complicated and not suitable for mass production. Further research shall propose simple design of SIP to facilitate mass production and attain commercialisation purposes.

\section{References}

1. Panjehpour M (2013) Structural Insulated Panels: Past, Present, and Future 3(1): 2-8.

2. Bhatti AQ (2016) Application of dynamic analysis and modelling of structural concrete insulated panels (SCIP) for energy efficient buildings in seismic prone areas. Energy and Buildings 128: 164-177.

3. Choi I, Kim J, You YC (2016) Effect of cyclic loading on composite behavior of insulated concrete sandwich wall panels with GFRP shear connectors. Composites Part B: Engineering 96: 7-19.

4. Meng Q Hao H, Chen W (2016) Laboratory test and numerical study of structural insulated panel strengthened with glass fibre laminate against windborne debris impact. Construction and Building Materials 114: 434-446.

5. Mugahed Amran YH (2016) Structural behavior of axially loaded precast foamed concrete sandwich panels. Construction and Building Materials 107: $307-320$.

6. Norris TG, Chen A (2016) Development of insulated FRP-confined Precast Concrete Sandwich panel with side and top confining plates and dry bond. Composite Structures 152: 444-454.
7. Panjehpour M (2014) Evaluation of Structural Insulated Wall Panels Behaviour Using Various Substituted Materials 1(2): 138-142.

8. Chen A (2015) Experimental investigation and finite element analysis of flexural behavior of insulated concrete sandwich panels with FRP plate shear connectors. Engineering Structures 98: 95-108.

9. Uddin N (2013) 12-Thermoplastic composite structural insulated panels (CSIPs) for modular panelized construction BT-Developments in Fiber-Reinforced Polymer (FRP) Composites for Civil Engineering', in Woodhead Publishing Series in Civil and Structural Engineering. Woodhead Publishing pp. 302-316.

10. Smakosz $Ł$, Tejchman J (2014) Evaluation of strength, deformability and failure mode of composite structural insulated panels. Materials \& Design (1980-2015) 54: 1068-1082.

11. Hopkin D J (2011) Full-scale natural fire tests on gypsum lined structural insulated panel (SIP) and engineered floor joist assemblies. Fire Safety Journal 46(8): 528-542.

12. Panjehpour M (2011) Frp Sheets Contribution in Common Repair Techniques of Concrete Structures With Emphasis on Concrete Columns. International Journal 2(2): 54-61.

13. Panjehpour M, Farzadnia N, Demirbog R, Ali AAA (2016) Behavior of high-strength concrete cylinders repaired with CFRP sheets. Journal of Civil Engineering and Management 22(1): 56-64.

14. Chen W, Hao H (2015) Performance of structural insulated panels with rigid skins subjected to windborne debris impacts - Experimental investigations. Construction and Building Materials 77: 241-252.

\section{(c) (P) This work is licensed under Creative}

To Submit Your Article Click Here: Submit Article

DOI: $10.32474 /$ TCEIA.2018.03.000151

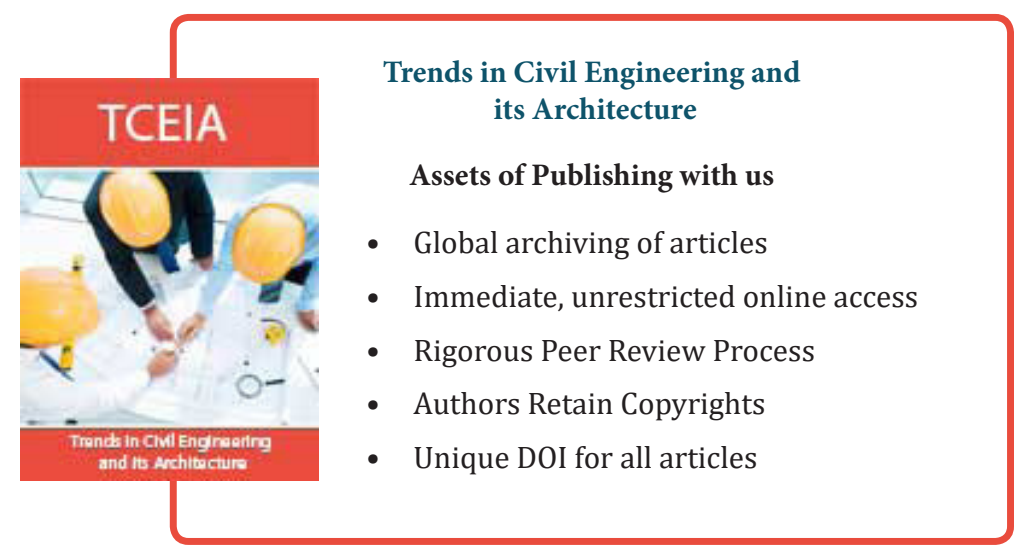

